\title{
Review of: "Impact of physical distancing policy on reducing transmission of SARS-CoV-2 globally: Perspective from government's response and residents' compliance"
}

\author{
FIRDOUS JAHAN
}

Potential competing interests: The author(s) declared that no potential competing interests exist.

COVID 19 is a global concern now, causing severe respiratory tract infections in humans. The current evidence indicates COVID-19 spread to humans through humans and wild animals. Asymptomatic spread also happens during family gatherings or at work place, thus, we need to enforce physical distancing as much as possible to reduce the spread of cases. Droplet transmission occurs when respiratory droplets generated via coughing, sneezing or talking comes into contact with susceptible mucosal surfaces, such as the eyes, nose or mouth. Social distancing measures are essential components of the public health response to influenza pandemics in past. Corona virus predominantly is transmitted by droplets from the mouths and noses of infected people when they cough or sneeze, which can land on surfaces and people's hands. Isolation and quarantine are the measures to break the cycle of spread. Social and physical distancing is one of the main components of the public health response to Corona pandemics.

Precautionary measures should be taken to prevent the virus from entering closed communities which can result in mass outbreaks. Forced social distancing is required for public compliance and cooperation to ensure effective implementation as government is making a law. Forced Social distancing practices can help stop the spread by reducing social contact at public places, avoiding mass gatherings (wedding, funeral), in order to delay transmission and reducing the extent of an outbreak. As a responsible citizen, people should follow Ministry of Health guidelines, avoiding overcrowding at public areas and attending unnecessary social gatherings, especially events with large numbers of people or crowds.

Social distancing can lead to spreading unhealthy rumors, misinformation and myths via social media and may cause anxiety and depression. To combat that, people should take time to focus on personal health training, physical activity levels and healthy dietary habits. The civic duty is to understand the gravity of the situation effecting on politics, business and public health while facing the pandemic of corona virus infection. People were not prepared for social distancing but over the time they have learnt to do so. Another issue is economic shut down which many people are facing right now but still many of them are compliant to government requirement of forced distancing. We can see the positive result of lockdown and forced physical distancing in Oman, the cases reduced remarkably with reduced hospital admission. This proves if government implement the law and people follow the guide lines for prevention, we can make a 
difference in terms of morbidity and mortality. We must be helping government in implementation of law, understand the gravity of the situation effecting on politics, business and public health while facing the pandemic of corona virus infection. People also need moral and financial support during the pandemic. Community support towards health officials are mandatory and effective to break the cycle. 